\title{
CLINICAL EXPERIENCE WITH THE E.M.O. INHALER
}

\author{
P. V. Cole, M.B., F.F.A.R.C.S.* James Parkhouse, M.A.(Oxon.), M.D., F.F.A.R.C.S. \\ Nuffield Department of Ancesthetics, The Radcliffe Infirmary, Oxford
}

DURING the last war the Oxford ether vaporizer facilitated anæsthesia in the absence of medical gases. The scope of ether/air anæsthesia can now be extended, and its difficulties avoided, by the use of muscle relaxants; with a quantitative inhaler and a means of inflating the lungs a good anæsthetic can be given for any operation.

The Oxford Vaporizer has been superseded by the E.M.O. Inhaler and the Oxford Inflating Bellows. These incorporate many technical improvements; in practice, their chief advantages are that the inhaler does not have to be filled with hot water, and that the bellows can be used alone to treat respiratory failure.

In this country the advantages of ether/air anæsthesia are obscured by the availability of medical gases, elaborate machines, and highly trained anæsthetists. Other countries are less fortunate: medical gases may be difficult to obtain; money may not be available for elaborate equipment, or even if this is provided the administrators' lack of experience may make it more of a liability than an asset. A comment from Japan (Wakai, personal communication) is typical of this: 'In one big hospital centre, an expensive foreign-made gas machine was installed many years ago, but the first patient to be anæsthetized with it having died, general anæsthesia had long been abandoned'.

The E.M.O. Inhaler, with the Oxford Inflating Bellows, provides a simple, logical answer to the problem of apparatus for general anæsthesia in all circumstances-in some it is almost the only feasible answer; but simplicity and logic have no ready appeal to the specialist who has grown up with a complex apparatus and learned to understand its behaviour. For this reason many doctors overseas who could most profitably use the E.M.O. Inhaler receive little encouragement from this country; indeed, they must often feel that since complex apparatus is used from choice in our leading hospitals it must have some strange advantage. Many countries have bought needlessly elaborate anæsthetic machines for their main

\footnotetext{
* Present address: St. Bartholomew's Hospital Medical School, London, E.C.I.
}

centres-at the expense of peripheral hospitalsas a reaction against the 'inferiority complex' associated with using a simple apparatus and an an old-fashioned drug.

A wise man, it is said, learns from experience, but a wiser learns from the experiences of others. We therefore wish to describe our experiences during a clinical trial of the E.M.O. Inhaler in a teaching centre in this country. All the anæsthetists in our hospitals, from house officer to consultant, used the apparatus and kept records of their cases. Some were already familiar with the Inhaler, but many learned as they went along. Frankness was encouraged in reporting difficulties and disadvantages. In all, 1,250 records were collected.

\section{Methods of Anæsthesia}

Ether, trichloroethylene, halothane, and the halothane-ether azeotropic mixture were used, in suitably calibrated E.M.O. Inhalers; all types of operation were performed; the patients were of all ages.

Three basic techniques were used:

A. Induction with a sleep dose of $2.5 \%$ thiopentone, or with a volatile agent, followed by maintenance with the agent of choice in air, administered through a face mask, the patient breathing spontaneously.

B. Induction with thiopentone and suxamethonium, followed by endotracheal intubation with or without preliminary cocanization of the larynx, anæsthesia then being maintained by spontaneous breathing of the selected volatile agent.

C. Induction with thiopentone or a volatile agent and a muscle relaxant, followed by endotracheal intubation and maintenance of anæsthesia with a minimum concentration of the selected volatile agent, full curarization and controlled ventilation.

When ether was used for induction it was given $N$ from the E.M.O. Inhaler; halothane or azeotrope induction was with the E.M.O. Inhaler or an open mask; in some cases open ethyl-chloride was used.

In group $A$ and $B$ cases, non-rebreathing was ensured either by using the O.I.B. and a standard expiratory valve, or by using a Ruben valve and immobilizing the outlet valve of the O.I.B. with the magnet.

For most cases in group $B$, a right-angled endotracheal connector was used with a hole drilled in the top. During the apnca following suxamethonium the patient's lungs were inflated by closing this hole with one finger while compressing the bellows, the finger 
being removed to allow expiration. At the return of spontaneous breathing the hole was closed with adhesive strapping and the standard expiratory valve was brought into use. In the remaining cases a Ruben valve was used.

Methods $A$ and $B$ were used for operations requiring a light plane of anæsthesia, without muscular relaxation. Muscle relaxants were not given, even in small doses, during the maintenance of anæsthesia with spontaneous breathing.

In some of the cases in group $\mathrm{C}$ suxamethonium was given for intubation, followed by a long-acting relaxant; others were intubated with the aid of d-tubocurarine or gallamine. A suxamethonium drip was used in a few cases. Intermittent positive pressure ventilation was carried out either manually or by a simplified Radcliffe type respiration pump. For manual ventilation either the Ruben or Mitchell valve was used, or the drilled endotracheal connector described above. All cases in group $\mathrm{C}$ were given atropine and neostigmine at the end of the operation. Method $C$ was used mainly for abdominal, pulmonary and cardiac surgery.

The concentrations of the various volatile agents needed for maintenance of anæsthesia are shown in Table I.

Ether/air and azeotrope/air mixtures were used in the presence of diathermy, but whenever oxygen was added to these mixtures diathermy was prohibited.

\section{Results}

Anæsthetists who were experienced with the E.M.O. Inhaler were able to avoid complications and provide satisfactory operating conditions at all times. However, in order to obtain clinical information for this trial some experienced users, with the surgeons' co-operation, deliberately incurred the risk of poor operating conditions or an unduly slow induction; this is reflected in the incidence of complications reported below. Anæsthetists with less experience of the apparatus encountered difficulties which will be discussed, as this may be helpful to others who wish to begin using the apparatus.

\section{Cyanosis}

This occurred at the time of intubation or extubation in 26 patients $(2.1 \%)$ and during the maintenance of anæsthesia in 92 patients $(7.4 \%)$.

At the time of intubation, cyanosis only occurred in some of the patients who were made apnœic and ventilated with room air before passing the laryngoscope. At the time of extubation, cyanosis occurred occasionally when the endotracheal tube was removed without previously administering oxygen.

The cases classed as having cyanosis during maintenance of anæsthesia include all those in which a tinge of cyanosis was noted at some stage; the great majority of these incidents were brief. Cyanosis was observed in 68 patients $(5.4 \%)$ who were operated on in the supine position; these included 12 patients with cardiac or respiratory disease. On 2 I occasions respiration was controlled; in 12 of these cases cyanosis was
TABLE I

Maintenance Concentrations of Volatile Agents

\begin{tabular}{|c|c|c|}
\hline Agent & $\begin{array}{l}\text { Light anæsthesia } \\
\text { with spontaneous } \\
\text { breathing } \\
\text { (Methods } \mathrm{A} \text { and } \mathrm{B} \text { ) }\end{array}$ & $\begin{array}{l}\text { Minimal anæsthesia } \\
\text { with full doses of } \\
\text { muscle relaxants } \\
\text { (Method C) }\end{array}$ \\
\hline $\begin{array}{l}\text { Ether } \\
\text { Halothane } \\
\text { Azeotrope* } \\
\text { Trilene . . }\end{array}$ & $\begin{array}{c}6-10 \% \\
1.5-2.5 \% \\
1.5-3 \% \\
1.5-2.5 \% \\
\text { (not recommended) }\end{array}$ & $\begin{array}{c}2-4 \% \\
0.5-1.0 \% \\
0.6-0.9 \% \\
0.4-0.75 \%\end{array}$ \\
\hline
\end{tabular}

* These are total concentrations, i.e. $0.6 \%$ azeotrope denotes $0.4 \%$ halothane with $0.2 \%$ ether.

quickly relieved by improved ventilation of the lungs, and in nine oxygen was added without improved ventilation being attempted. Cyanosis during spontaneous breathing, which occurred in 47 cases, was also relieved either by adding oxygen or by assisting ventilation. In defence of diethyl ether, it should be noted that of the 2 I occasions on which spontaneous breathing was thought to require assistance all but one occurred during halothane or azeotrope anæsthesia.

Cyanosis occurred during maintenance of anæsthesia in 24 patients who were in the Trendelenburg, lithotomy or lateral position, and in seven who had large abdominal swellings, ascites or gross obesity.

\section{Hypotension}

As muscle relaxants were freely available, deep general anæsthesia was rarely used; hypotension was therefore uncommon. The systolic pressure fell below $80 \mathrm{~mm}$. $\mathrm{Hg}$ on 20 occasions with halothane $(6.4 \%$ of the halothane cases) and on $2 \mathrm{I}$ occasions with the azeotrope $(4.4 \%)$. No significant falls in blood pressure occurred with ether or trichloroethylene.

With one exception, every episode of hypotension was associated with the administration of a higher concentration of the anæsthetic than would be required for maintenance in the curarized patient. The exception was a hypotensive attack associated with paroxysmal auricular fibrillation; this occurred during azeotrope/air anæsthesia with gallamine in a patient who had a history of such attacks.

\section{Recovery}

After controlled ventilation, there was some delay in the return of spontaneous breathing on 30 occasions, but the longest period of supervision required was only 20 minutes. In four of these cases the anæsthetist thought the difficulty to be due to the muscle relaxant, and in three cases to over-generous or ill-timed premedication. In 13 cases it was almost certainly due to overdosage of the volatile agent by an inexperienced 
administrator; this happened once with ether, six times with halothane and five times with the azeotrope. The ten episodes not thus accounted for were all brief, and all occurred towards the beginning of the trial. These were most probably the result of over-ventilation.

\section{Miscellaneous Complications}

In 30 cases $(2.4 \%)$ it was noted that induction was too slow, or that anæsthesia was too light when the operation began. In ten of these cases anæsthesia was induced with ether/air mixtures; in the others induction was with halothane or the azeotrope, and the difficulty was attributable to inexperience. Again, in 17 cases anæsthesia was allowed to become too light during the operation -a further manifestation of inexperience. This occurred five times with ether, nine times with halothane and three times with the azeotrope.

Shivering was seen six times during recovery from halothane/air anæsthesia.

Attempts to provide satisfactory operating conditions for herniotomy and similar procedures with trilene/air mixtures alone, depending on the patient's spontaneous breathing, were unsatisfactory. Low concentrations of trichloroethylene, with muscle relaxants and controlled respiration throughout the operation, were followed by rapid awakening even after long procedures, but there was some tendency to post-operative drowsiness. These trilene/air cases will be reported in more detail elsewhere.

One patient died on the operating table; this was a poor-risk, emphysematous patient who developed a tension pneumothorax during controlled ventilation and failed to recover even after decompression of the pleural space.

\section{Discussion}

When full doses of a muscle relaxant are given and a very light plane of anæsthesia is maintained with controlled ventilation, results with the E.M.O. Inhaler are no different from those with nitrous oxide and oxygen; the patient awakens rapidly at the conclusion of surgery and the choice of anæsthetic agent is of little consequence. Freedom from dependence on soda lime, and the ability to give any desired concentration of oxygen in an emergency without fear of the patient awakening, are real advantages.

When the patient breathes spontaneously and a volatile agent alone is used to provide adequate operating conditions, maintenance of anæsthesia with the E.M.O. and O.I.B. presents no problem once the administrator has had a little practice. The commonest mistake with ether/air is to try to use too little once the patient appears to be settled. It is not often possible to reduce the maintenance concentration below $7 \%$, except to- ڤ wards the end of prolonged operations, and very 3 rarely can it be reduced below $5 \%$ to $6 \%$. Higher $\stackrel{\mathbb{Q}}{\varrho}$ concentrations of ether, or $3 \%$ to $4 \%$ halothane,.. can be used for abdominal surgery if the anæs- $\overrightarrow{\vec{F}}$ thetist is prepared to assist respiration or use $\stackrel{?}{?}$ supplementary oxygen, but when muscle relaxants are available it is far better to use them.

Induction with ether/air is always slow. $A \frac{\overline{\frac{\rho}{D}}}{\sigma}$ smooth induction can be achieved with the $\AA$ E.M.O., but this takes at least ten minutes and $\%$ sometimes considerably longer. It is necessary $\vec{\circ}$ to raise the ether concentration to $15 \%$ and allow the patient to breathe this strength for at least $\vec{\omega}$ five minutes before he can be relied upon to $\frac{\rho}{0}$ tolerate a strong surgical stimulus.

A rapid induction can be achieved with halothane and the patient will then tolerate high con- 0 centrations of ether immediately. It is possible to $\mathrm{c}$ have the patient breathing $15 \%$ ether within two or three minutes of applying the face mask, but he will not necessarily tolerate a skin incision at 0 this time. He must still be allowed to breathe $15 \%$ ether for at least five minutes before the concentration is reduced for maintenance. A Goldman type vaporizing bottle, or one of the $\stackrel{5}{\stackrel{5}{\longrightarrow}}$ several similar halothane units, may conveniently $\underset{\vec{\oplus}}{\stackrel{+}{+}}$ be interposed between the E.M.O. and the O.I. for induction.

A preliminary injection of thiopentone pleasant for the patient, but does not greatly accelerate ether/air induction. However, if the thiopentone is followed by suxamethonium and the patient's lungs are then ventilated with $10 \% \stackrel{\mathbb{Q}}{\complement}$ to $15 \%$ ether through a cuffed endotracheal tube, $\vec{O}$ surgical anæsthesia can be obtained rapidly. $\frac{}{3}$ When spontaneous breathing is resumed the patient will tolerate the endotracheal tube and the operation can begin. Here, the commonest mistake is failure to introduce enough ether into the 3 . circulation during apnœa, with the result that the $\frac{\dot{0}}{7}$ patient coughs when the effect of the suxamethonium wears off. ECG studies have shown that 8 the danger of reflex disturbance during inflation

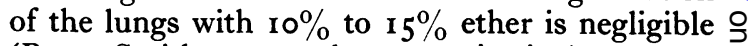
(Bryce-Smith, personal communication).

The success of anæsthesia with the E.M.O. is absolutely dependent on effective tidal exchange. N Therefore, when a respiratory depressant drug such as halothane is administered with air, $\tilde{N}$ cyanosis due to respiratory depression is an everpresent possibility. With the azeotropic mixture the chances of respiration remaining adequate are 0 somewhat greater, and with ether, greatest of all. $\mathbb{D}$ It need hardly be added that even small doses of $\stackrel{\infty}{+}$ a muscle relaxant, given to a spontaneously breathing patient, are likely to result in an inadequate tidal exchange. 
In this series, and in the experience of other E.M.O. users, the only patients who fail to maintain a satisfactory colour during spontaneous breathing with ether/air mixtures are those with respiratory embarrassment due to position on the operating table, extreme obesity or abdominal swelling, and some with severe cardiovascular or respiratory disease. In these cases ventilation can always be assisted or controlled, and there is naturally no objection to giving additional oxygen if this is available. Even during controlled ventilation the need for vigorous inflation of the lungs - especially in the steep Trendelenburg positionis not sufficiently appreciated, and can readily be masked by giving an oxygen-enriched mixture.

When breathing must be depressed or interrupted, cyanosis will develop more rapidly after air breathing than after oxygen breathing. This is apparent, for example, during intubation of the apnoic patient, and sometimes during extubation. In the present series, cyanosis at the time of intubation could always have been avoided by previously filling the lungs with oxygen. Even if oxygen is not available, a tinge of cyanosis during intubation is of no consequence as long as adequate ventilation is immediately resumed. Extubation is often followed by transient breathholding or laryngospasm, and a fall in arterial oxygen saturation is liable to occur with any method of anæsthesia unless the lungs have previously been filled with oxygen (Cole and Parkhouse, $196 r$ ). If repeated intra-tracheal suction is liable to be necessary during maintenance of anæsthesia in the patient who has been made apnœic, it is clearly advisable to use supplementary oxygen. Similarly, although it is not always necessary, the anæsthetist who undertakes thoracic work with the E.M.O. Inhaler should be prepared to use supplementary oxygen, and this will entail prohibiting the use of diathermy if ether is the only drug available.

\section{Summary}

A general account is given of the results of a small clinical trial of the E.M.O. Inhaler and Oxford Inflating Bellows.

When muscle relaxants are available, controlled ventilation of the patient's lungs with $2 \%$ to $4 \%$ ether through a cuffed endotracheal tube provides ideal operating conditions for abdominal and thoracic surgery, and constitutes a form of anæs- thesia virtually indistinguishable in its effects from the conventional nitrous oxide-oxygencurare combination. The ether may be vaporized in room air, and supplementary oxygen is unnecessary. If a suitable, calibrated inhaler is available, trichloroethylene, halothane, or the azeotropic mixture may be used in a low concentration for the same purpose.

During thoracic surgery, or when repeated intra-tracheal suction is required, supplementary oxygen may be necessary. If ether is used, diathermy must then be prohibited.

During spontaneous breathing, cyanosis need not be anticipated with ether/air anæsthesia in the healthy patient who is operated on in the supine position. During halothane/air anæsthesia, however, there may be sufficient respiratory depression to cause cyanosis. If the patient is in the Trendelenburg, lithotomy, or lateral position, or if his diaphragmatic excursions are restricted by an abdominal tumour, ascites, or gross obesity, spontaneous breathing during anæsthesia is likely to be inadequate. The respiration should be assisted, or supplementary oxygen should be given. In patients with respiratory or circulatory disease the same measures may be required even in the supine position.

Anæsthesia can be induced rapidly with thiopentone followed by a short-acting muscle relaxant such as suxamethonium; a cuffed endotracheal tube can then be passed and ether can be introduced rapidly into the circulation by ventilation of the lungs with $10 \%$ to $15 \%$ during the period of apnœa. Sufficient ether can be introduced to ensure that when the patient begins breathing again he will accept the endotracheal tube without coughing and will tolerate a surgical incision. The E.M.O. Inhaler can then be relied upon to supply a maintenance concentration of ether without any attention other than ensuring that the vaporizing chamber is not empty; the valves of the O.I.B. ensure a non-rebreathing system, and there need be no fear of cylinders becoming empty. With the airway assured by an endotracheal tube this constitutes the ideal form of anæsthesia, when muscular relaxation is not required, for the practitioner who must work with inadequate assistance, or for the doctor who must entrust maintenance of anæsthesia to a nurse or orderly while performing the operation himself.

\section{REFERENCE}

Cole, P. V,. and Parkhouse, J. (I96I): Blood Oxygen Saturation during Anæsthesia with Volatile Agents Vaporized in Room Air, Brit. F. Anasth., 33, 265. 